\title{
Detection of Particulate Matter Changes Caused by 2020 California Wildfires Based on GNSS and Radiosonde Station
}

\author{
Jinyun Guo ${ }^{1} \mathbb{D}$, Rui Hou ${ }^{1}$, Maosheng Zhou ${ }^{1, * \mathbb{D}}$, Xin Jin $^{1}$ and Guowei Li ${ }^{2}$ \\ 1 College of Geodesy and Geomatics, Shandong University of Science and Technology, Qingdao 266590, China; \\ guojy@sdust.edu.cn (J.G.); hourui@sdust.edu.cn (R.H.); skdjinxin1010@sdust.edu.cn (X.J.) \\ 2 Department of Space and Technology, Shandong Provincial Institute of Land Surveying and Mapping, \\ Jinan 250100, China; ligw@shandong.cn \\ * Correspondence: zhoumaosheng2018@sdust.edu.cn
}

check for updates

Citation: Guo, J.; Hou, R.; Zhou, M.; Jin, X.; Li, G. Detection of Particulate Matter Changes Caused by 2020 California Wildfires Based on GNSS and Radiosonde Station. Remote Sens. 2021, 13, 4557. https://doi.org/ $10.3390 /$ rs13224557

Academic Editor: Stefania Bonafoni

Received: 26 October 2021

Accepted: 10 November 2021

Published: 12 November 2021

Publisher's Note: MDPI stays neutral with regard to jurisdictional claims in published maps and institutional affiliations.

Copyright: (c) 2021 by the authors. Licensee MDPI, Basel, Switzerland. This article is an open access article distributed under the terms and conditions of the Creative Commons Attribution (CC BY) license (https:// creativecommons.org/licenses/by/ $4.0 /)$.

\begin{abstract}
From August to October 2020, a serious wildfire occurred in California, USA, which produced a large number of particulate matter and harmful gases, resulting in huge economic losses and environmental pollution. Particulate matter delays the GNSS signal, which affects the like precipitable water vapor (LPWV) derived by the GNSS non-hydrostatic delay. Most of the information of GNSS-derived LPWV is caused by water vapor, and a small part of the information is caused by particulate matter. A new method based on the difference ( $\triangle \mathrm{PWV}$ ) between the PWV of virtual radiosonde stations network and GNSS-derived LPWV is proposed to detect the changes of particulate matter in the atmosphere during the 2020 California wildfires. There are few radiosonde stations in the experimental area and they are far away from the GNSS station. In order to solve this problem, we propose to use the multilayer perceptron (MLP) neural network method to establish the virtual radiosonde network in the experimental area. The PWV derived by the fifth-generation European center for medium-range weather forecasts reanalysis model ( $P W V_{E R A 5}$ ) is used as the input data of machine learning. The PWV derived by radiosonde data (PWV RAD) is used as the training target data of machine learning. The $\triangle \mathrm{PWV}$ is obtained based on PWV derived by the virtual radiosonde station network and GNSS in the experimental area. In order to further reduce the influence of noise and other factors on $\triangle \mathrm{PWV}$, this paper attempts to decompose $\triangle \mathrm{PWV}$ time series by using the singular spectrum analysis method, and obtain its principal components, subsequently, analyzing the relationship between the principal components of $\triangle \mathrm{PWV}$ with particulate matter. The results indicate that the accuracy of PWV predicted by the virtual radiosonde network is significantly better than the fifth-generation European center for the medium-range weather forecast reanalysis model, and the change trend of $\triangle \mathrm{PWV}$ is basically consistent with the change law of particulate matter in which the value of $\triangle \mathrm{PWV}$ in the case of fire is significantly higher than that before and after the fire. The mean of correlation coefficients between $\triangle \mathrm{PWV}$ and PM10 at each GNSS station before, during and after wildfires are $0.068,0.397$ and 0.065 , respectively, which show the evident enhancement of the correlation between $\triangle \mathrm{PWV}$ and particulate matter during wildfires. It is concluded that because of the high sensitiveness of $\triangle \mathrm{PWV}$ to the change of particulate matter, the GNSS technique can be used as an effective new approach to detect the change of particulate matter and, then, to detect wildfires effectively.
\end{abstract}

Keywords: global navigation satellite system; 2020 California wildfires; virtual radiosonde stations network; multilayer perceptron neural network; PM10/PM2.5

\section{Introduction}

In 2020, huge wildfires that raged through California killed 91 people, and fiercer wildfires occur in the western United States more frequently [1], impinging on the ecosystem. Additionally, wildfires cannot only cause great economic damage, but also produce incalculable impacts on the environment. Therefore, the research on wildfires detection methods 
grows in popularity. Wildfires produce a large number of smoke particles [2], of which PM10 (particles from 0 microns to 10 microns) and PM2.5 (particles from 2.5 microns or less) are considered as two important indicators, affecting human health. Long-term exposure to particles seriously damages human bodies. Anjali et al. studied the Australian wildfires in 2019, concluding through experimenters that long-term exposure to wildfires smoke has a serious impact on the respiratory tract [3]. Angeliki et al. collected statistics on particulate matter from 1980 to 2020. Moreover, it was concluded that PM10 and PM2.5 concentrations are associated with mortality, and that the risk of cardiovascular death and the incidence rate of the respiratory system will mount with the increase in PM2.5 concentration in smoke [4]. The occurrence of wildfires is often triggered by natural causes such as heatwaves and droughts in summer and lightning, as well as smoking, picnics, and other human activities [5,6]. Wildfires are unpredictable and harmful. The earlier detection of wildfires can significantly alleviate the impact on people and the loss [7,8]. Antonio et al. developed a layered wireless sensor network, which is combined with originated wildfires in dangerous areas and integrated with a fire command center, geographic information system, and fire detector so as to detect wildfires [9]. Hu et al. applied Sentinel-2 remote sensing data to classify wildfire areas and non-fire areas, and established a fully automatic algorithm based on adaptive thresholds which can be applied to onboard processing [10]. Taking the 2020 California wildfires as the research object, Alan et al. modeled 54 million wildfires and 25 million building locations in the study area, conducting a risk assessment and experiments for wildfire prediction [11]. Currently, the research methods of wildfire detection mainly use unmanned aerial vehicles, remote sensing, various smoke sensors, etc., but these methods have the disadvantages of a huge cost and poor real-time performance.

The Global Navigation Satellite System (GNSS) has been widely used in the field of meteorology by virtue of its advantages of wide distribution of stations, all-weather observation, low cost, and high temporal and spatial resolution [12-15]. The content of precipitable water vapor (PWV) in the atmosphere changes sharply with time and space [16-18], so the PWV is widely used in meteorology research [19-21]. The GNSS-derived PWV (PWV GNSS) has been verified, and its accuracy is the same as that of traditional technologies such as a radiosonde station, airborne radiometer, water vapor radiometer, and lidar [22,23]. Moreover, Abbasy et al. conducted experiments on GNSS stations in the province of Zanjan,

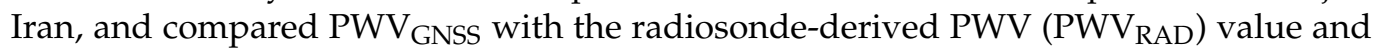
PWV value in the global reanalysis datasets [24]. It has been concluded that GNSS inversion PWV has a better inversion accuracy. Yahaya et al. studied the correlation between GNSS inversion PWV and particulate matter in Nigeria, and determined statistics on the correlation between GNSS inversion PWV and particulate matter PM10 [25]. It has been concluded that GNSS inversion PWV and PM10 are highly correlated. Guo et al. studied the correlation between the inversion of the zenith total delay (ZTD) and PM2.5 by GNSS, and predicted the particulate matter PM2.5 in short-term, proving the influence of the GNSS-based inversion on ZTD, including particulate matter [26]. Wen et al. verified the relationship between the zenith wet delay and PM2.5 based on GNSS and meteorological factors, and predicted the PM2.5 value in short-term [27]. The feasibility of particle detection based on GNSS has been proved by relevant research.

The GNSS signal is delayed due to the influence of the troposphere. The hydrostatic delay can be obtained by the tropospheric model with millimeter accuracy, mainly considering the influence of the standard atmosphere without particles such as PM10/PM2.5. Therefore, the influence of particulate matter is included in the non-hydrostatic delay [26] and GNSS-derived like PWV(LPWV). Most of the information of GNSS-derived LPWV is caused by water vapor, and a small part of the information is caused by particulate matter. The PWV observed by the radiosonde station is mainly caused by water vapor, without being affected by particles. Therefore, the difference $(\triangle \mathrm{PWV})$ between GNSS-derived LPWV and PWV RAD is mainly caused by particles in theory [28]. Because of a few available ground sounding stations without colocation, this paper proposes a method to detect 
the change of atmospheric particles during the 2020 California wildfires by obtaining the $\triangle \mathrm{PWV}$ based on the PWV of virtual sounding stations and GNSS stations.

This paper aims to use the GNSS technique to detect particulate matter changes caused by the 2020 California wildfires. A new method based on the $\triangle \mathrm{PWV}$ between the PWV of the virtual radiosonde stations network and GNSS-derived LPWV is proposed. The relationship between particulate matter and $\triangle \mathrm{PWV}$ is studied. Section 2 introduces study areas, data collection and research methods. Processing results and analyses are presented in Section 3. Finally, the conclusion is given in Section 4.

\section{Data and Research Methods}

\subsection{Study Area}

California is a wildfire hot spot in the western United States [29]. In order to deal with the occurrence of wildfires, California's fire prevention budget has mounted year by year, but still cannot solve the problem of wildfires. The most destructive wildfires recorded broke out in the 21st century [30]. Since August 2020, another wildfire consumed swathes of California with a burned area of more than 2.09 million acres (about 8457 square kilometers), reaching an all-time high. The 2020 California wildfires have led to huge economic losses and environmental pollution.

As California is located in the west of the Rocky Mountains and positioned in the Mediterranean climate zones, it is affected by anticyclones caused by Pacific high pressure in summer with dry air and little rainfall, which is very prone to triggering wildfires. In winter, affected by the Pacific moderation, it belongs to the wet season (from December to April), and the precipitation on the windward slope (west slope) is abundant [31]. Heatwaves and dryness in summer can induce wildfires easily, so California has become a hot spot of wildfires in the world.

\subsection{Research Data}

\subsubsection{Wildfire Data}

The wildfires map provided by National Aeronautics and Space Administration (NASA) is shown in Figure 1b (https: / / firms.modaps.eosdis.nasa.gov/map Access date: 6 September 2021). The wildfires mainly occur in northern California with a large area and long duration. Additionally, the wildfires mainly happen in August, September, and October, of which the area of wildfires in September is regarded as the largest. According to the area of the wildfires, the area with longitude from $113^{\circ} \mathrm{W}$ to $124^{\circ} \mathrm{W}$ and latitude from $33^{\circ} \mathrm{N}$ to $41^{\circ}$, mainly in California, was chosen for the current study. The distribution of GNSS stations, air quality monitoring stations, and ground radiosonde sounding stations is shown in Figure 1.

\subsubsection{GNSS Data}

Based on wildfire information, 10 GNSS stations in California were selected as the research data which were taken from the Système d'Observation du Niveau des Eaux Littorales (SONEL) website (https:/ / www.sonel.org/ Access date: 6 September 2021). The GNSS data only included GPS data with a 30s data sampling interval and a data length from day 001 of year 2020 to day 366 of year 2020. The distribution of selected GNSS stations is shown in Figure 1b.

The Global Positioning System(GPS) data processing strategy is shown in Table 1.

The GPS data were processed based on the data processing strategy in Table 1. The solution average accuracy of GNSS-derived ZWD and GNSS-derived LPWV at each site is shown in Table 2. According to Table 2, the average accuracy of ZWD and LPWV at ten GNSS stations in the experimental area from 001 days to 366 days in 2020 was between $3.09 \mathrm{~mm} \sim 4.53 \mathrm{~mm}$ and $0.52 \mathrm{~mm} \sim 0.75 \mathrm{~mm}$, respectively. The solution accuracy met the requirements. 
Table 1. The Global Positioning System (GPS) data processing strategy.

\begin{tabular}{cc}
\hline Parameters & Value \\
\hline Cut-off height angle & $10^{\circ}$ \\
Tropospheric model & Saastamoinen \\
Mapping function & GMF \\
Tropospheric parameter estimation interval & $1 \mathrm{~h}$ \\
Ocean tide model & Fes2004 \\
Epoch interval & $30 \mathrm{~s}$ \\
Solar pressure model & BERNE \\
\hline
\end{tabular}

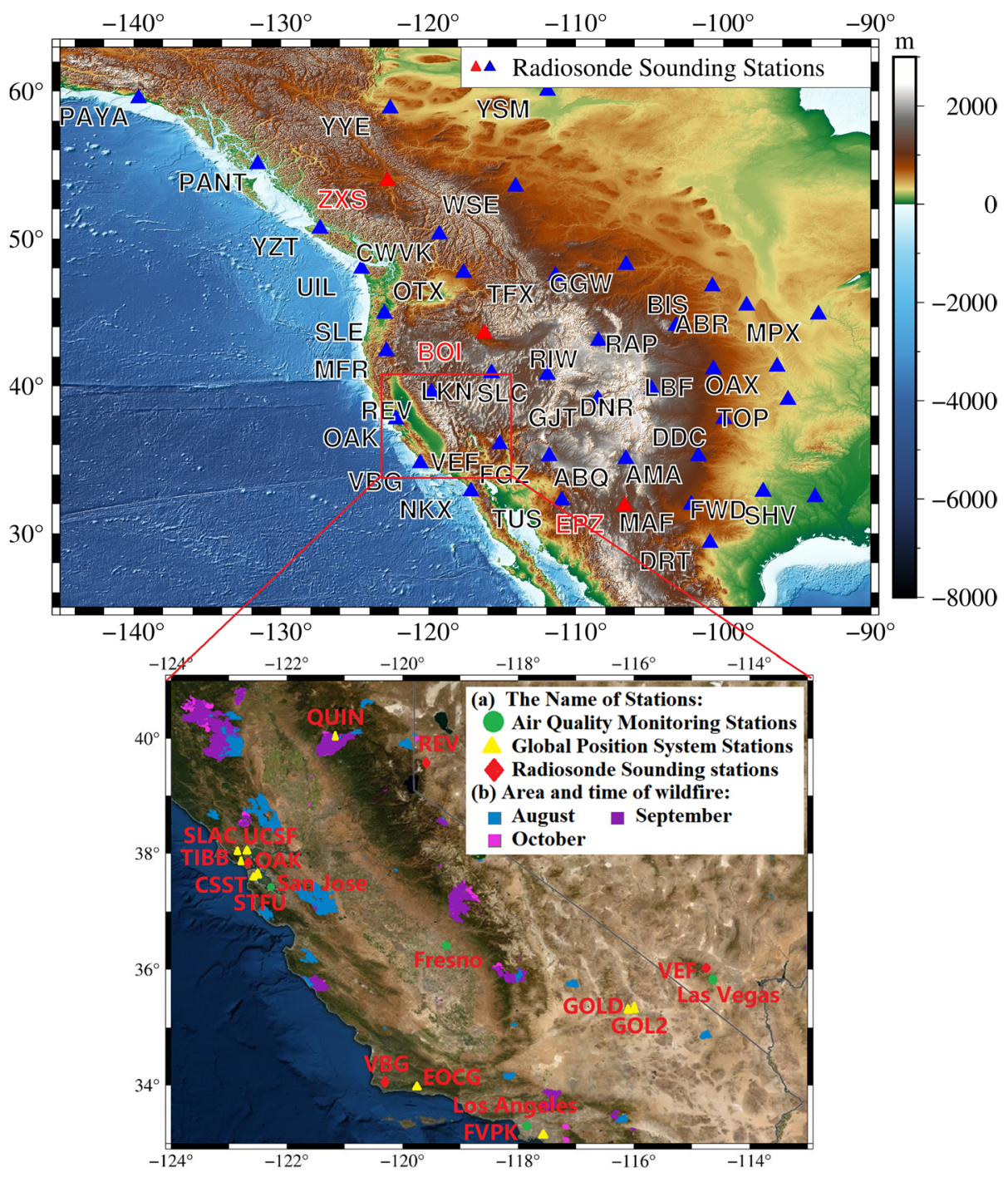

Figure 1. Global Navigation Satellite System (GNSS) stations, radiosonde sounding stations, and air quality monitoring stations.

Table 2. The average accuracy of GNSS-derived zenith wet delay (ZWD) and GNSS-derived like precipitable water vapor $(\mathrm{LPWV})(\mathrm{mm})$.

\begin{tabular}{ccc}
\hline Site & GNSS-Derived ZWD & GNSS-Derived LPWV \\
\hline QUIN & 4.03 & 0.67 \\
GOLD & 4.02 & 0.66 \\
GOL2 & 4.07 & 0.68 \\
FVPK & 3.98 & 0.66 \\
\hline
\end{tabular}


Table 2. Cont.

\begin{tabular}{ccc}
\hline Site & GNSS-Derived ZWD & GNSS-Derived LPWV \\
\hline SLAC & 3.09 & 0.52 \\
TIBB & 4.18 & 0.70 \\
UCSF & 4.53 & 0.75 \\
STFU & 4.49 & 0.74 \\
CSST & 4.37 & 0.73 \\
EOCG & 4.28 & 0.73 \\
\hline
\end{tabular}

\subsubsection{Air Quality Data}

The PM10/PM2.5 data were selected to indicate the wildfire situation, which were taken from the global air quality data platform (https:/ /aqicn.org/data-platform/register/ Access date: 6 September 2021) with the data period from day 001 of year 2020 to day 366 of year 2020. The global air quality data platform provides an average of PM data every day. The distribution of selected air quality stations is shown in Figure $1 b$.

\subsubsection{PWV Data}

The $\mathrm{PWV}_{\mathrm{RAD}}$ data were derived from the measured data of radiosonde stations (http:/ / weather.uwyo.edu/upperair/sounding.htm Access date: 6 September 2021). This paper adopted four radiosonde stations in which the observation data at 0:00 am every day was taken as the experimental data with the data period from day 001 of year 2016 to day 366 of year 2020, with its geographical distribution shown in Figure 1a,b.

The PWV derived by the fifth-generation European center for medium-range weather forecasts reanalysis model (ERA5) dataset (https://cds.climate.copernicus.eu/cdsapp\# !/ dataset/reanalysis-era5-single-levels?tab=form Access date: 6 September 2021) was also used in this study. The ERA5 uses physical laws to combine the model data with the observation results throughout the world to form a global complete dataset [32-34]. The ERA5 can provide PWV data extending from the earth's surface to the top of the atmosphere. Thereinto, data grid size was $0.25^{\circ}$ and the time resolution was $24 \mathrm{~h}$. Moreover, the data at 0:00 (UTC) in a day was taken as the experimental data in this study with the data period from day 001 of year 2016 to day 366 of year 2020 .

Due to the systematic error between ERA5-derived PWV (PWV ERA5) and PWV $\mathrm{PAD}_{\text {, in }}$ order to establish the PWV network model of virtual radiosonde station, the PWV data of radiosonde sounding stations in the Rockies were used as the neural network learning data to train PWV $\mathrm{ERA}_{\mathrm{E} 5}$, so as to construct the PWV model of virtual radiosonde station in the Rockies of California and eliminate the systematic error. The PWV data in radiosonde station were derived from the Department of Atmospheric Science at the University of Wyoming (http:/ / weather.uwyo.edu/upperair/sounding.html Access date: 6 September 2021). The data were measured twice at 0:00 am (UTC) and 12:00 am every day, and the research period was selected from day 001 of year 2016 to day 366 of year 2020, a total of five years. The distribution of selected radiosonde stations is shown in Figure 1a, where ZXS, BOI and EPZ were self-inspection data.

\subsection{Research Methods}

\subsubsection{Acquirement of $\triangle \mathrm{PWV}$}

GAMIT 10.74 was used to process GPS data for obtaining GNSS-derived LPWV. The principle was that the total tropospheric delay (ZTD) was taken as an unknown parameter and solved by the GNSS carrier phase observation equation. GNSS phase observation equation was [35]:

$$
L_{i, f}^{j}=\rho_{i}^{j}+c\left(d t_{i}-d t^{j}\right)+M \cdot Z \mathrm{TD}-I_{i, f}^{j}+\lambda_{f} N_{i, f}^{j}+\varepsilon_{i, f}^{j}
$$


where $I, j$, and $f$ denote the satellite, receiver, and signal frequency, respectively. $\rho_{i}^{j}$ denotes the geometry distance from receiver to satellite. $c$ represents the speed of light in vacuum. $d t_{i}$ and $d t^{j}$ are the receiver clock offset and the satellite clock offset, respectively. $M$ is the mapping function of troposphere. The ZTD and $I_{i, f}^{j}$ denote the total tropospheric delay and the slant ionosphere delay. $N_{i, f}^{j}$ and $\lambda_{f}$ are the phase ambiguity and the wavelength of phase observation. $\varepsilon_{i, f}^{j}$ denotes other unmodelled errors.

The ZTD can be expressed as:

$$
\mathrm{ZTD}=\left[L_{i, f}^{j}-\rho_{i}^{j}-c\left(d t_{i}-d t^{j}\right)+I_{i, f}^{j}-\lambda_{f} N_{i, f}^{j}-\varepsilon_{i, f}^{j}\right] / M
$$

The ZTD is the zenith total delay, including the delay caused by standard dry atmosphere, water vapor, and particulate matter. The ZHD was calculated using the Saastamoinen model [36]. The equation was:

$$
\mathrm{ZHD}=\frac{0.0022768 P}{1-0.00266 \operatorname{COS}(2 L)-0.00028 H}
$$

where $P$ denotes atmospheric pressure. $L$ denotes latitude. $H$ denotes the GPS station geodetic height. The ZHD is a delay due to standard dry atmosphere. The standard dry atmosphere did not include PM10, PM2.5, and other particles. Finally, zenith nonhydrostatic delay (also known as zenith wet delay, ZWD) could be calculated by:

$$
\mathrm{ZWD}=\mathrm{ZTD}-\mathrm{ZHD}
$$

Therefore, the delay caused by water vapor and particles was included in ZWD. The GNSS-derived LPWV could be calculated by [37]:

$$
\begin{gathered}
\mathrm{LPWV}=\mathrm{ZWD} \cdot \sigma \\
\sigma=\frac{10^{6}}{\rho_{w} g_{s}\left[k_{2}+\left(\frac{k_{3}}{T_{m}}\right)\right]}
\end{gathered}
$$

where $\sigma, T_{m}$ and $\rho_{w}$ are the conversion factor, the weighted average temperature of the troposphere, and the density of liquid water. $g_{s}=461 \mathrm{~J} \cdot \mathrm{kg}^{-1} \mathrm{~K}^{-1} \cdot k_{2}=16.48 \mathrm{~K} / \mathrm{hPa}$, $k_{3}=105 \mathrm{~K}^{2}(3.776 \pm 0.014) / \mathrm{hPa}$.

Since GNSS-derived LPWV was calculated according to ZWD, GNSS-derived LPWV would also be affected by particles.

The PWV $\mathrm{RAD}_{\mathrm{R}}$ threes directly calculated by meteorological parameters, so it threes only caused by water vapor and threes not affected by particles. In order to deduct the influence of water vapor in GNSS-derived LPWV, the PWV RAD threes introduced.

The relative humidity $(\mathrm{U})$ and the saturated water vapor pressure $(\mathrm{E})$ of radiosonde data should have been used to calculate the precipitable water pressure $(e)$ [38] to obtain

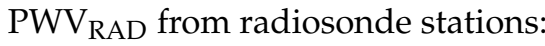

$$
e=\frac{\mathrm{UE}}{100}
$$

The specific humidity $(q)$ was obtained according to water vapor pressure:

$$
q=\frac{\varepsilon \mathrm{e}}{\mathrm{p}-\mathrm{e} *(1-\varepsilon)}
$$

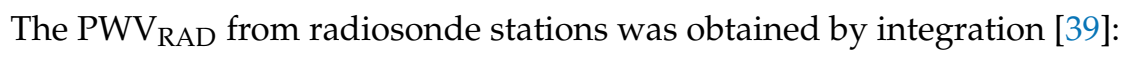

$$
\mathrm{PWV}_{\mathrm{RAD}}=\frac{1}{g} \int_{0}^{p_{0}} q d p
$$


where, $\varepsilon=0.622 \mathrm{gkg}^{-1}$ as an empirical constant. $p$ and $p_{0}$ represent pressure of different heights measured by the sounding balloon sensor. $g$ is gravitational acceleration. The PWV $\mathrm{RAD}_{\mathrm{D}}$ was calculated from the measured meteorological data. Therefore, the influence of particulate matter was not included.

Therefore, the $\triangle \mathrm{PWV}$ affected by particulate matter was expressed as:

$$
\Delta \mathrm{PWV}=\mathrm{LPWV}-\mathrm{PWV}_{\mathrm{RAD}}
$$

The $\triangle P W V$ was obtained through the calculation from Equations (1) to (10) above. Theoretically, $\triangle \mathrm{PWV}$ was caused by particles. The occurrence of fire would produce a large number of smoke particle pollutants such as PM2.5 and PM10. Therefore, the correlation between $\triangle \mathrm{PWV}$ and PM10/PM2.5 could be used to detect wildfires.

\subsubsection{Establishment Methods of Virtual Radiosonde Station Networks}

Since only 4 radiosonde stations were available in the area of the wildfires without colocation with GNSS stations, this situation affected the calculation of $\triangle \mathrm{PWV}$. In this study, establishing PWV network of virtual radiosonde stations based on multilayer perceptron (MLP) neural network was proposed. Thereinto, the PWV ERA5 data at the radiosonde stations provided by the European center for medium-range weather forecasts, the longitude, latitude and elevation of GNSS station, as well as the annual and the day of year (doy) of PWV data, were used as training input data. Moreover, the PWV RAD value at radiosonde stations was used as the learning target data. As the experimental area was located in the west of the Rockies and close to the Pacific Ocean, the terrain fluctuated greatly. To validate the science of virtual radiosonde network, the PWV $\mathrm{ERA5}_{\text {and the PWV }}$ RAD at 40 radiosonde stations were used as input data and learning target data for training. Radiosonde stations are distributed around North American Rockies (as shown in Figure 1). The period of PWV data was doy 001 of 2016 to doy 366 of 2020. The geographical distribution of radiosonde stations used for training and verification is shown in Figure 1a.

The MLP neural network is defined as a distributed algorithm mathematical model for information processing based on the interaction of a large number of neurons with the characteristics of self-adaptive, self-learning, and real-time learning. The MLP neural network is generally composed of input layer, hidden layer, and output layer, in which there are a large number of nodes connected by weight between each network layer [40]. When MLP neural network receives a group of input signals, it performs nonlinear weight calculation through activation function, and transmits the calculation results to the next neuron. Because the initial weight is randomly generated, the output value reaches the predetermined goal by continuously adjusting the weight between each neuron in the training process.

The MLP neural network model constructed in this study is shown in Figure 2, in which the input layer contained 6 parameters-year, doy, latitude, longitude, geodetic height, and 0:00 (UTC) PWV ERA5; 2 hidden layers were included in the middle, and the

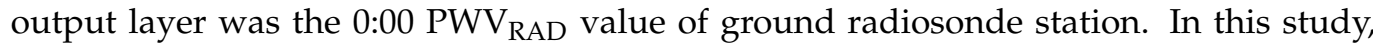
Levenberg-Marquart (LM) algorithm was used for neural network training. The LM algorithm has proved to be an optimization algorithm with excellent performance, strong convergence, and high precision by combining the strengths of gradient method and Newton-Raphson method. In this study, it was used for neural network fitting training algorithm, eliminating the systematic error between PWV $V_{\text {ERA5 }}$ and PWV the accuracy of PWV ERA5.

\subsubsection{Singular Spectrum Analysis (SSA)}

In theory, the $\triangle \mathrm{PWV}$ was influenced by particulate matter. However, the LPWV could be affected by climate temperature and precipitation. Therefore, it was also affected by many other factors besides particles. Since the singular spectrum analysis (SSA) method could decompose the one-dimensional sequence into a series of time series with their characteristics, such as tendency, cycle, and noise, it was possible to extract the trend, 
identify the period of the original time series, and smooth the data [41-44]. Therefore, the SSA was used to decompose $\triangle \mathrm{PWV}$ to obtain its principal component. The technical route is shown in Figure 3.

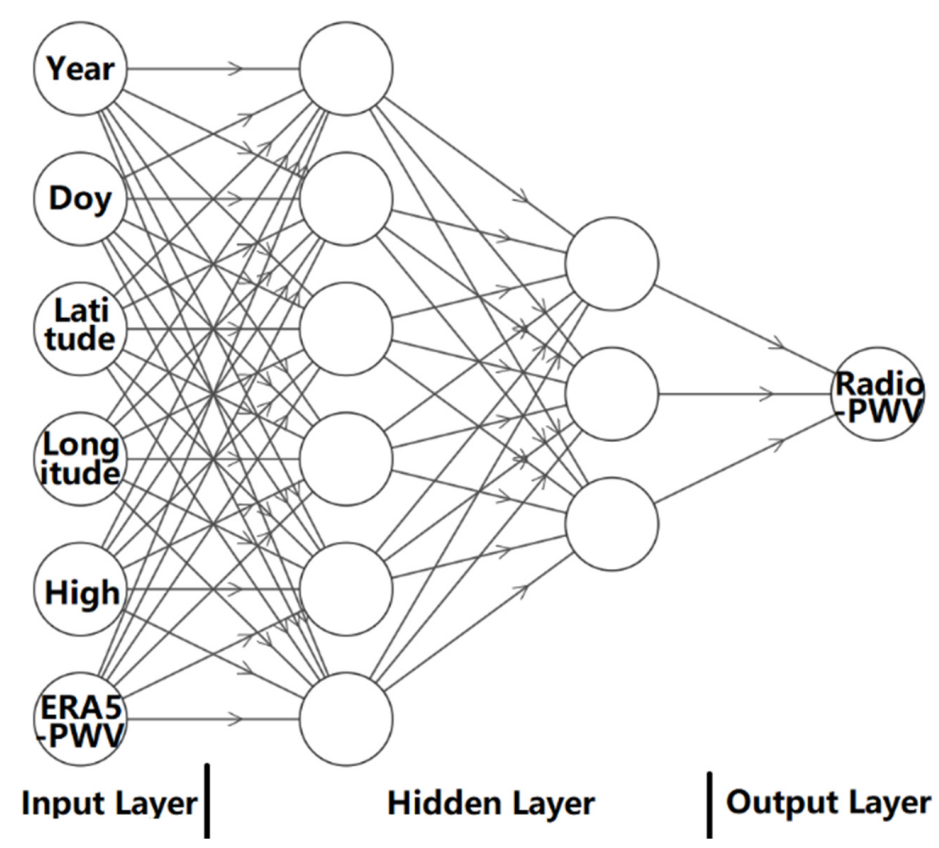

Figure 2. Structure chart of neural network.

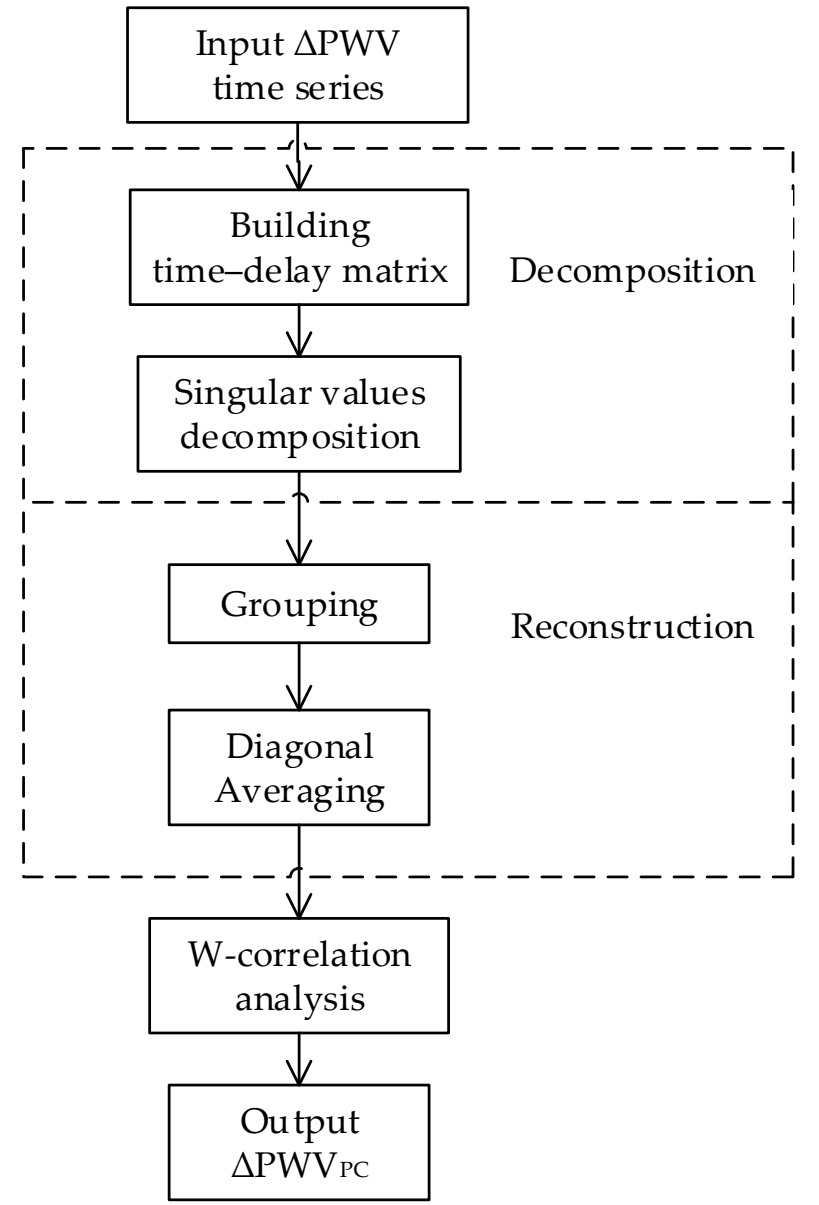

Figure 3. The main steps of singular spectrum analysis (SSA) analysis. 
As shown in Figure 3, first, input $\triangle \mathrm{PWV}$ time series. Second, the construction of delay matrix. In general, oscillations with periods of $M / 5 \sim M$ could be well recognized when the window length was $\mathrm{M}$. Third, singular value decomposition, which could construct a new matrix by choosing its eigenvalues and eigenvectors. The fourth grouping divided the original time series into disjoint groups. Fifth, diagonal averaging, the purpose of which was to convert the decomposed primary matrix back into a new time series of the original length, called the reconstruction component $(\mathrm{RC})$, and the sum of all the $\mathrm{RC}$ values equaled the original sequence. Sixth, the correlation analysis of all RCs was carried out, and the principal components were determined.

\section{Result and Analysis}

\subsection{Accuracy Analysis of PWV of Virtual Radiosonde Station Network}

In order to verify the accuracy of the virtual radiosonde station network PWV $\left(\mathrm{PWV}_{\mathrm{VR}}\right)$, the fitting rate $(\mathrm{R})$ of the neural network and performance of machine learning at different stages of learning were analyzed, and the results are shown in Table 3 and Figure 4. It can be seen from Figure 4 that the fitting rate of the regression analysis in the training stage, validation stage, test stage, and the whole process was $0.977,0.987,0.984$, and 0.979 , respectively. The mean squared error (MSE) in the training stage, validation stage, test stage, and the whole process was $3.12 \mathrm{~mm}, 1.17 \mathrm{~mm}$, and $1.37 \mathrm{~mm}$, respectively. The results show that the effect of machine learning was good.

Table 3. Performance of machine learning.

\begin{tabular}{cccc}
\hline Progress & Samples & MSE $(\mathbf{m m})$ & Fitting Rate \\
\hline Training & 52,428 & 3.12 & $97.75 \%$ \\
Validation & 6554 & 1.17 & $98.77 \%$ \\
Testing & 6554 & 1.37 & $98.41 \%$ \\
\hline
\end{tabular}

In order to further analyze the accuracy of $\mathrm{PWV}_{\mathrm{VR}}, \mathrm{PWV}_{\mathrm{VR}}$, and PWV $\mathrm{PRA}_{\mathrm{E} 5}$ at ZXS (the radiosonde in the northern of the virtual radiosonde network), BOI (the radiosonde station in the central of the virtual radiosonde network), and EPZ (the radiosonde station in the south of the virtual radiosonde network) were selected to compare with the $P W V_{R A D}$, respectively. The root mean square error (RMS), mean, and standard deviation (STD) were calculated, respectively. The correlations between PWV $\mathrm{VRA}_{\text {E } 5}$ and $P W V_{R A D}$, and $P W V_{V R}$ and $P W V_{R A D}$ were analyzed, respectively. The statistical results are listed in Table 4.

Table 4. PWV of virtual radiosonde station network $\left(\mathrm{PWV}_{\mathrm{VR}}\right)$ accuracy analysis.

\begin{tabular}{|c|c|c|c|c|c|c|}
\hline Station & Latitude $\left({ }^{\circ}\right)$ & Longitude $\left({ }^{\circ}\right)$ & $\begin{array}{c}\text { Geodetic } \\
\text { Height (m) }\end{array}$ & Parameter & $\begin{array}{l}\text { PWV ERA5 and } \\
\text { PWV } \\
\text { RAD }(\mathrm{mm})\end{array}$ & $\begin{array}{c}\text { PWV }_{\text {VR }} \text { and } \\
\text { PWV }_{\text {RAD }}(\mathrm{mm})\end{array}$ \\
\hline \multirow{4}{*}{ ZXS } & \multirow{4}{*}{53.9} & \multirow{4}{*}{-122.79} & \multirow{4}{*}{601} & RMS & 2.16 & 1.75 \\
\hline & & & & STD & 1.85 & 1.75 \\
\hline & & & & MEAN & 1.11 & 0.05 \\
\hline & & & & CORREL & 0.98 & 0.99 \\
\hline \multirow{4}{*}{ BOI } & \multirow{4}{*}{43.56} & \multirow{4}{*}{-116.21} & \multirow{4}{*}{874} & RMS & 0.93 & 0.72 \\
\hline & & & & STD & 0.91 & 0.72 \\
\hline & & & & MEAN & -0.11 & -0.08 \\
\hline & & & & CORREL & 0.98 & 0.99 \\
\hline \multirow{4}{*}{ EPZ } & \multirow{4}{*}{31.86} & \multirow{4}{*}{-106.7} & \multirow{4}{*}{1252} & RMS & 1.02 & 0.79 \\
\hline & & & & STD & 0.97 & 0.79 \\
\hline & & & & MEAN & 0.31 & 0.04 \\
\hline & & & & CORREL & 0.98 & 0.99 \\
\hline
\end{tabular}


(a)

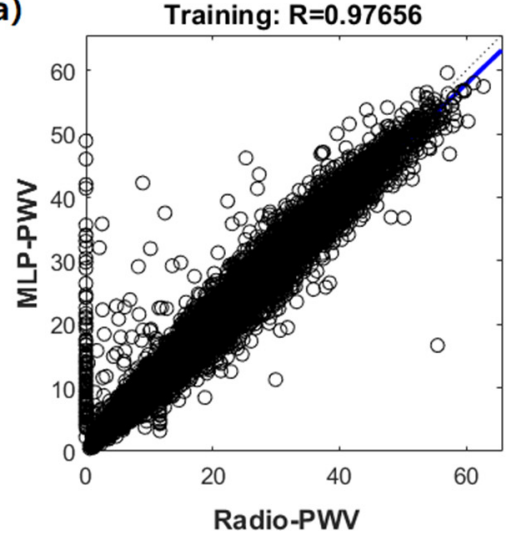

(c)

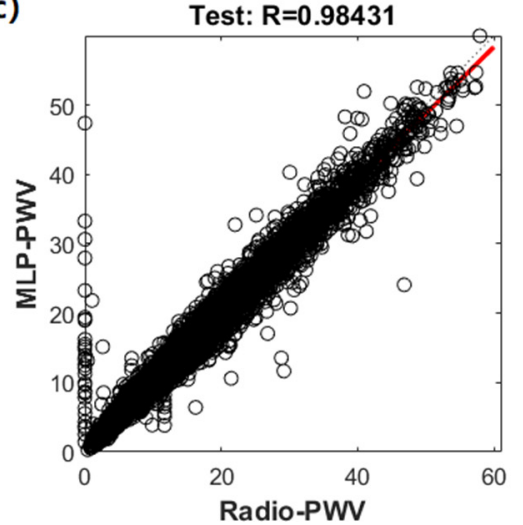

(b)

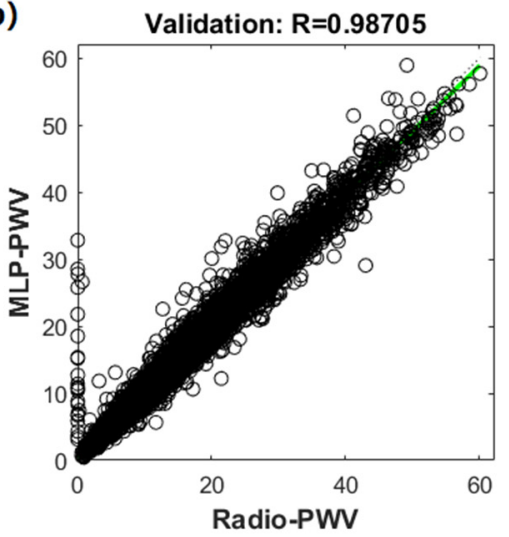

(d)

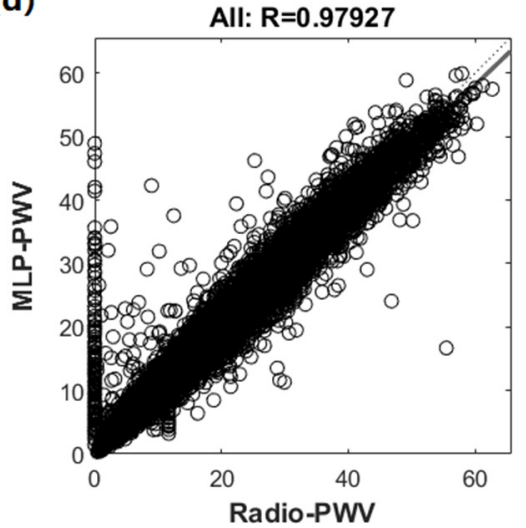

Figure 4. Learning effect of multilayer perceptron (MLP) neural network (the horizontal axis is the PWV of the radiosonde station, the vertical axis is the PWV of machine learning, and the oblique line is the fitting line).

According to the statistics, compared with the RMS, STD, and mean of the difference between PWV $\mathrm{VRA}_{\text {ER } 5}$ and PWV $\mathrm{V}_{\mathrm{RAD}}$, those of the difference between PWV $\mathrm{VR}_{\mathrm{V}}$ and $P W V_{\mathrm{RAD}}$ at the three radiosonde stations were reduced by $21.37 \%, 14.95 \%$, and $69.95 \%$, respectively, with particularly obvious improvement in the mean value. This shows that the system error between $P W V_{E R A 5}$ and $P W V_{R A D}$ could be greatly reduced by establishing a virtual radiosonde station network, so that the accuracy of PWV $\mathrm{ERA}_{5}$ can be improved. It can be seen from the above statistical results that the accuracy of $\mathrm{PWV}_{\mathrm{VR}}$ was obviously better than that of PWV $\mathrm{ERA5}_{\text {. Therefore, }} \mathrm{PWV}_{\mathrm{VR}}$ could be used to replace the $P W V_{\mathrm{RAD}}$ value of the radiosonde station to calculate $\triangle \mathrm{PWV}$.

\subsection{Detection of Change of Particulate Matter Based on $\triangle P W V$}

Firstly, based on $\mathrm{PWV}_{\mathrm{VR}}$ in the Rocky Mountain region of the United States, the $\triangle \mathrm{PWV}$ of each GNSS station at hour 0 (UTC) each day was obtained, and the mean of $\triangle \mathrm{PWV}$ of each period before, during, and after the fire was calculated. The variation of the mean of $\triangle \mathrm{PWV}$ in different fire stages was analyzed, and the statistical results were listed in Table 5.

As is listed in Table 5, the mean of $\triangle \mathrm{PWV}$ at each GNSS station was higher than that before the fire, which was mainly due to the significant increase in $\triangle \mathrm{PWV}$ caused by a large amount of particulate matter generated during the fire. The $\triangle \mathrm{PWV}$ before the wildfire of the seven GNSS stations was higher than that after the wildfire, such as QUIN. This was mainly due to the rainy season from January to April every year. After the fire, there was less rainfall in the dry season in this area. Due to the special climatic factors, the $\triangle \mathrm{PWV}$ in the seven GNSS stations was higher in the early period than in the later period of the wildfire. The $\triangle \mathrm{PWV}$ of the three GNSS stations, including STFU in the later stage of fire, was larger than that in the earlier stage, possibly because the three GNSS stations 
were located at the junction of the Coast Mountains and Tehachapi Mountains, with no high mountains blocking them. Under the influence of the Pacific humid airflow all year round [45], and because the GNSS stations on both sides were close to the fire burning area, the particles after the fire remained in the air for a long time.

Table 5. Statistics of mean of the difference ( $\triangle \mathrm{PWV}$ ) between the PWV of virtual radiosonde stations network and GNSS-derived LPWV in different fire periods $(\mathrm{mm})$.

\begin{tabular}{cccc}
\hline GNSS & Before Fire & During Fire & After Fire \\
\hline QUIN & 2.42 & 3.51 & 2.36 \\
GOLD & 3.67 & 4.50 & 2.90 \\
GOL2 & 3.63 & 4.44 & 2.88 \\
FVPK & 1.84 & 3.57 & 1.24 \\
SLAC & 1.76 & 4.11 & 1.42 \\
TIBB & 1.57 & 4.02 & 1.42 \\
UCSF & 3.87 & 6.25 & 3.47 \\
STFU & 1.80 & 3.69 & 2.50 \\
CSST & 1.05 & 3.33 & 2.79 \\
EOCG & 0.98 & 2.21 & 2.47 \\
\hline
\end{tabular}

There were four air quality monitoring stations distributed in the study area. San Jose only provided PM2.5 data, while the other three stations provide PM10 and PM2.5 data. This paper determined statistics on PM10 data of the four air quality stations according to the maximum value, average value, and STD before and after the fire. The results are listed in Table 6, from which it can be concluded that PM10 was maximum at the time of fire occurrence. The PM10 concentration after the wildfire was higher than that before the wildfire, which was consistent with the change trend of wildfire, indicating that PM10 data could be used to characterize the change of wildfire.

Table 6. The PM10 statistics of air quality stations in different fire periods $\left(\mu \mathrm{g} / \mathrm{m}^{3}\right)$.

\begin{tabular}{ccccc}
\hline Air Station & Parameter & Before Fire & During Fire & After Fire \\
\hline \multirow{3}{*}{ San Jose } & STD & 10.09 & 38.77 & 15.83 \\
& MEAN & 25.53 & 58.08 & 36.20 \\
& MAX & 57.00 & 180.00 & 85.00 \\
\hline \multirow{3}{*}{ Los Angeles } & STD & 15.21 & 26.01 & 14.75 \\
& MEAN & 43.82 & 68.38 & 55.38 \\
& MAX & 94.00 & 159.00 & 90.00 \\
\hline \multirow{2}{*}{ Fresno } & STD & 10.19 & 29.77 & 19.31 \\
& MEAN & 23.07 & 69.71 & 32.61 \\
& MAX & 59.00 & 164.00 & 79.00 \\
\hline \multirow{2}{*}{ Las Vegas } & STD & 7.52 & 10.72 & 8.16 \\
& MEAN & 18.84 & 32.72 & 20.66 \\
& MAX & 57.00 & 67.00 & 43.00 \\
\hline
\end{tabular}

In order to analyze the relationship between $\triangle \mathrm{PWV}$ and PM more directly, the variation trend of $\triangle \mathrm{PWV}$ and PM2.5 at the SLAC station and STFU station in different fire periods was studied. The two GNSS stations were close to the San Jose Air Quality Station, and the PM2.5 data of San Jose Air Quality Station were taken to characterize the change of fire. The monthly mean of $\triangle \mathrm{PWV}$ at the two GNSS stations and the monthly mean of PM2.5 at the air quality station were analyzed. The results are shown in Figure 5, where the red box is the time of fire occurrence. 


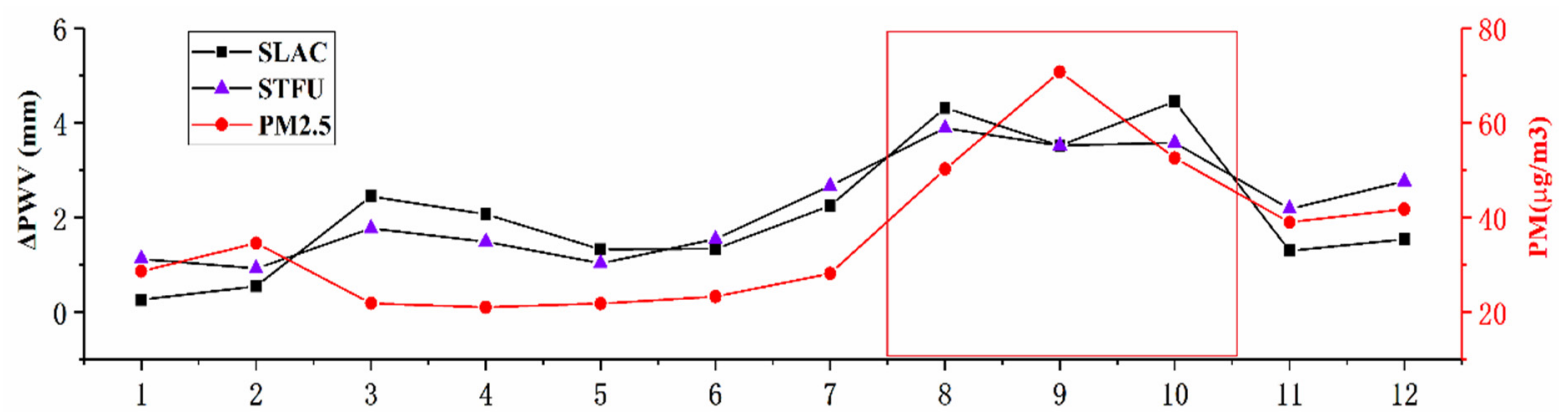

Figure 5. Comparison of monthly mean values of $\triangle \mathrm{PWV}$ and PM2.5 at SLAC and STFU stations (the fire period is in the box).

As is shown in Figure 5, before the fire, $\triangle \mathrm{PWV}$ and PM2.5 of the two GNSS stations were small with steady change. Since May, PM2.5 and $\triangle \mathrm{PWV}$ were on the rise. From August to October, when fires broke out on a large scale, PM2.5 reached the peak, and $\triangle \mathrm{PWV}$ also rose rapidly to the peak, both changing dramatically. After October, the PM2.5 and the $\triangle \mathrm{PWV}$ showed a trend of rapid decline, and then stabilized after November. As can be seen from the above results, $\triangle \mathrm{PWV}$ was highly consistent with the change of PM2.5, and the change of PM2.5 could be detected by $\triangle \mathrm{PWV}$.

\subsection{Analysis of the Detection of Wildfires by $\triangle P W V$ Based on $S S A$}

However, due to the complex composition of water vapor, the $\triangle \mathrm{PWV}$ may also be affected by other factors. Therefore, $\triangle \mathrm{PWV}$ was decomposed by SSA to obtain the $\triangle \mathrm{PWV}$ principle component $(\triangle \mathrm{PWV} \mathrm{PC})$, and the effects of other factors (except particulate matter) on $\triangle \mathrm{PWV}$ were reduced as much as possible. The window length selected in this study was 90 .

In order to select the principal component, firstly, the eigenvalue contribution rate was analyzed. As shown in Figure 6, the results show that the eigenvalue contribution rate of the first $\mathrm{RC}$ in the $\triangle \mathrm{PWV}$ decomposition results was more than $87 \%$. Theoretically, most of the signals contained in the $\triangle \mathrm{PWV}$ were caused by particles, so this result was reasonable.
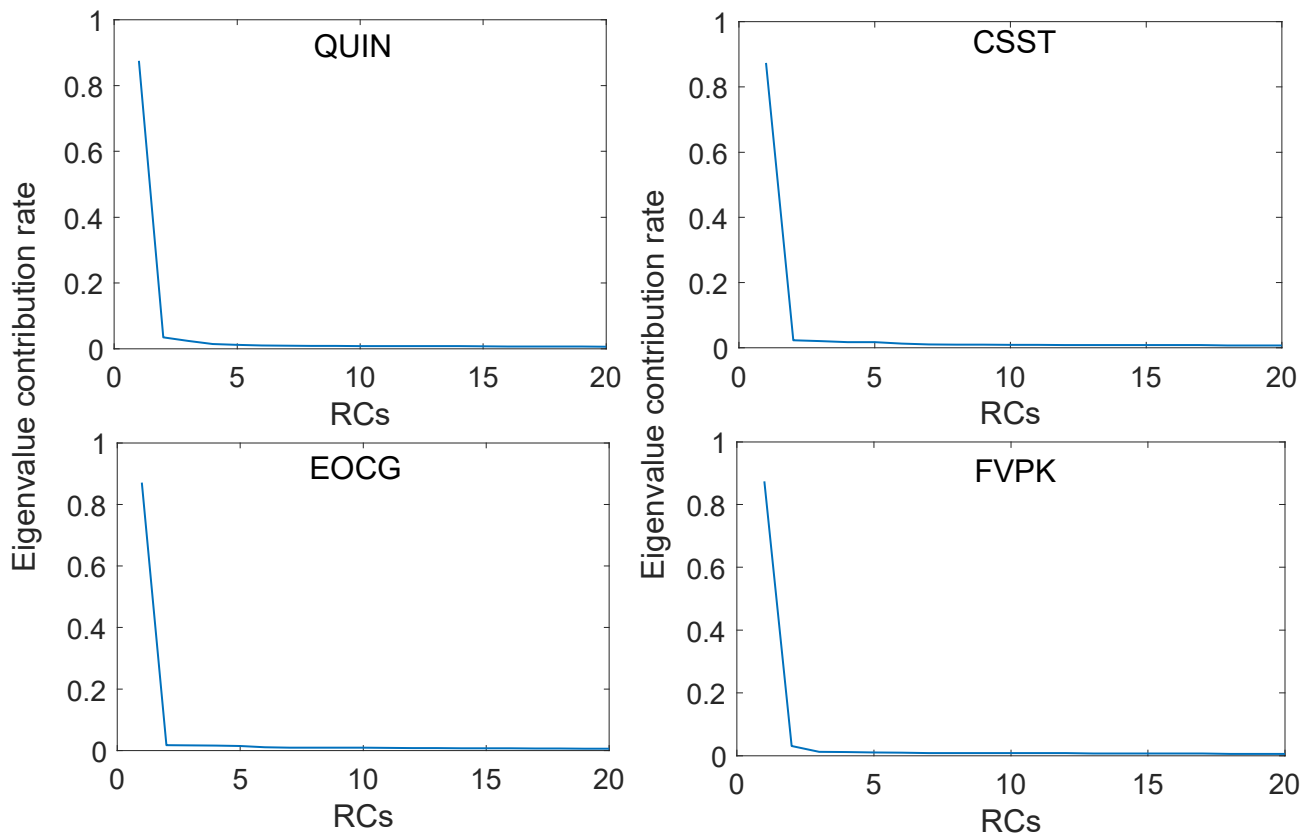

Figure 6. Eigenvalue contribution rate.

This paper, respectively, took the first one to ten order RCs as $\triangle \mathrm{PWV} P \mathrm{PC}$ and analyzed the correlation between each $\triangle \mathrm{PWV}$ PC and PM10. The results show that it could achieve 
the best effect when the first RCs were taken as $\triangle P W V_{P C}$. Therefore, the first RCs of the decomposition results were taken as $\triangle \mathrm{PWV}$ PC. The undecomposed $\triangle \mathrm{PWV}$ and $\Delta \mathrm{PWV} \mathrm{PC}_{\mathrm{PC}}$ were analyzed for correlation with PM10 data, respectively, and the results are listed in Table 7.

Table 7. Correlation comparison between PM10 data and $\triangle \mathrm{PWV}$ before and after reconstruction.

\begin{tabular}{ccc}
\hline GNSS & $\begin{array}{c}\text { Correlation Coefficient between } \\
\Delta \mathbf{P W V} \text { and PM10 }\end{array}$ & $\begin{array}{c}\text { Correlation Coefficient between } \\
\Delta \mathbf{P W V}_{\mathbf{P C}} \text { and PM10 }\end{array}$ \\
\hline GOL2 & 0.11 & 0.53 \\
GOLD & 0.12 & 0.55 \\
STFU & 0.21 & 0.46 \\
SLAC & 0.19 & 0.43 \\
TIBB & 0.25 & 0.49 \\
UCSF & 0.22 & 0.45 \\
QUIN & 0.10 & 0.58 \\
CSST & 0.35 & 0.56 \\
EOCG & 0.19 & 0.55 \\
FVPK & 0.21 & 0.59 \\
\hline
\end{tabular}

As is listed in Table 7, by using SSA to extract the principle components, the correlation coefficient between $\triangle \mathrm{PWV}$ PC and PM10 was $209.65 \%$ higher than the correlation between $\triangle \mathrm{PWV}$ and PM10. It could be concluded that after SSA reconstruction, the influence of non-particulate matter on $\triangle \mathrm{PWV}$ was significantly reduced, and the contribution rate of particulate matter to $\triangle \mathrm{PWV}$ was significantly increased.

Taking QUIN, CSST, EOCG, and FVPK as examples, the correlation analysis of $\triangle \mathrm{PWV}_{\mathrm{PC}}$ in different periods of fire with PM10 and PM2.5 was conducted, respectively. The statistical results are listed in Table 8.

Table 8. The correlation analysis of $\triangle \mathrm{PWV}$ principle component $\left(\triangle \mathrm{PWV} \mathrm{PC}_{\mathrm{PC}}\right.$.

\begin{tabular}{cccc}
\hline GNSS & Fire Period & PM10 & PM2.5 \\
\hline \multirow{3}{*}{ QUIN } & Before the fire & 0.082 & -0.525 \\
& During the fire & 0.413 & 0.310 \\
& After the fire & 0.309 & -0.007 \\
\hline \multirow{3}{*}{ CSST } & Before the fire & 0.027 & 0.175 \\
& During the fire & 0.418 & 0.321 \\
& After the fire & 0.377 & 0.295 \\
\hline \multirow{2}{*}{ EOCG } & Before the fire & 0.117 & 0.257 \\
& During the fire & 0.412 & 0.281 \\
& After the fire & -0.164 & -0.202 \\
\hline \multirow{2}{*}{ FVPK } & Before the fire & 0.045 & 0.182 \\
& During the fire & 0.346 & 0.310 \\
& After the fire & -0.260 & -0.064 \\
\hline
\end{tabular}

As is listed in Table 8, the correlation coefficient between $\triangle \mathrm{PWV}$ PC and PM10 and PM2.5 increased significantly when fire occurred, which indicates that $\triangle \mathrm{PWV}$ based on the virtual radiosonde station network was feasible to detect the change of particulate matter. Additionally, it was also effective to detect the change of particulate matter. In addition, the correlation coefficient between PM10 and $\triangle \mathrm{PWV}$ increased the most, indicating that in the particulate matter produced by the fire, the content of PM10 was larger than that of PM2.5.

\section{Conclusions}

The study took the 2020 California wildfires as an example, and the data of doy 001 to 366 in 2020 from 10 GNSS stations were calculated to obtain LPWV. A new method base on $\triangle \mathrm{PWV}$ to detect the changes of particulate matter in the atmosphere during the 
2020 California wildfires was proposed. The results showed that the variation trend of $\triangle \mathrm{PWV}$ was highly consistent with that of particulate matter data, with a high correlation between them.

The specific conclusions are as follows:

(1) The virtual radiosonde station network in the Rocky Mountain region was constructed based on the MLP neural network. The accuracy of PWV VR was significantly higher than that of PWV $\mathrm{VRA}_{\mathrm{E} 5}$, and the system deviation between PWV $\mathrm{VRA}_{\mathrm{ER}}$ and PWV could be greatly reduced.

(2) The $\triangle \mathrm{PWV}$ at fire occurrence was significantly higher than that at early and late stages of fire occurrence, showing the same change pattern with particulate matter.

(3) The $\triangle \mathrm{PWV}_{\mathrm{PC}}$ was obtained by decomposing and reconstructing $\triangle \mathrm{PWV}$ with the SSA method. The correlation coefficient between $\triangle \mathrm{PWV} \mathrm{PC}_{\mathrm{PC}}$ and particulate matter data was significantly improved, showing that the decomposition and reconstruction of $\triangle \mathrm{PWV}$ by SSA can significantly increase the contribution rate of particulate matter to $\triangle \mathrm{PWV}$. At the same time, the correlation coefficient between $\triangle \mathrm{PWV} \mathrm{PC}_{\mathrm{C}}$ and particulate matter data was significantly higher during the fire occurrence period than before and after the fire occurrence.

In conclusion, the $\triangle \mathrm{PWV}$ method based on the virtual radiosonde station network could effectively detect the change of particulate matter and, thus, provides a new technology and method for wildfire detection.

Author Contributions: J.G.: Conceptualization, Methodology, Funding acquisition; R.H.: Data curation, Software, Writing—original draft preparation. M.Z.: Validation, Investigation, Writing-reviewing and editing. X.J.: Software, Validation. G.L.: Supervision. All authors have read and agreed to the published version of the manuscript.

Funding: This study was supported by the National Natural Science Foundation of China (grant nos. 41774001, 41374009), SDUST Research Fund (grant no. 2014TDJH101), and Autonomous and Controllable Special Project for Surveying and Mapping of China (grant no. 816-517).

Institutional Review Board Statement: Not applicable.

Informed Consent Statement: Not applicable.

Data Availability Statement: The GNSS observation data used in our work can be freely accessed at https:/ / www.sonel.org/ Access date: 6 September 2021. The PWV RAD data were obtained from http:/ / weather.uwyo.edu/upperair/sounding.html Access date: 6 September 2021. The PWVERA5 data were obtained from https:/ / cds.climate.copernicus.eu/cdsapp\#!/dataset/reanalysis--era5-single--levels?tab=form Access date: 6 September 2021. The air quality monitoring data were obtained from https://aqicn.org/data-platform/register/ Access date: 6 September 2021. The forest fire information was obtained from https:/ / firms.modaps.eosdis.nasa.gov/map / Access date: 6 September 2021.

Acknowledgments: We are very grateful to SONEL for providing the GPS data. We are very grateful to the ECMWF and the University of Wyoming for providing the PWV data. We thank NASA for providing the wildfire information. We are very grateful to the global air quality data platform for providing the PM data. We thank the Massachusetts Institute of Technology (MIT), Scripps Institution of Oceanography (SIO), and Harvard University for providing GAMIT/GLOBK software. This research was supported by the National Natural Science Foundation of China (grant numbers 41774001) and the SDUST Research Fund (grant number 2014TDJH101).

Conflicts of Interest: The authors declare no conflict of interest.

\section{References}

1. Stephens, S.L.; Wagtendonk, J.W.; Agee, J.K.; Wakimoto, R.H. Introduction to the article by Harold Biswell: Prescribed burning in Georgia and California compared. Fire Ecol. 2021, 17, 9. [CrossRef]

2. O'Loughlin, C.; Jones, S.C.; Jenkins, M.; Gordon, C.E. The effects of inter-fire interval on flora-fauna interactions in a sub-alpine landscape. For. Ecol. Manag. 2020, 473, 118316. [CrossRef] 
3. Anjali, H.; Lex, W.D.; John, D.W.; Louis, I.; Jeanie, L.Y. Wildfire smoke exposure and respiratory health outcomes in young adults born extremely preterm or extremely low birthweight. Environ. Res. 2021, 197, 0013-9351.

4. Angeliki, K.; Andrés, A.; Fulvio, A.; Matteo, R.; Massimo, S.; Aurelio, T.; Cristina, R.; Francesco, F.; Sophie, G.; Pierpaolo, M.; et al. Short-term health effects from outdoor exposure to biomass burning emissions: A review. Sci. Total. Environ. 2021, 781, 0048-9697.

5. Kolář, T.; Kusbach, A.; Čermák, P.; Štěrba, T.; Batkhuu, E.; Rybníček, M. Climate and wildfire effects on radial growth of Pinus sylvestris in the Khan Khentii Mountains, north-central Mongolia. J. Arid. Environ. 2020, 182, 104223. [CrossRef]

6. Allen, C.D.; Savage, M.; Falk, D.A.; Suckling, K.F.; Swetnam, T.W.; Schulke, T.; Stacey, P.B.; Morgan, P.; Hoffman, M.; Klingel, J.T. Ecological restoration of southwestern ponderosa pine ecosystems: A broad perspective. Ecol. Appl. 2002, 12, 1418-1433. [CrossRef]

7. Abatzoglou, J.T.; Williams, A.P. Impact of anthropogenic climate change on wildfire across western US forests. Proc. Natl. Acad. Sci. USA 2016, 113, 11770-11775. [CrossRef]

8. Abatzoglou, J.T.; Balch, J.K.; Bradley, B.; Kolden, C.A. Human-related ignitions concurrent with high winds promote large wildfires across the USA. J. Int. Assoc. Wildland Fire 2018, 27, 377-386. [CrossRef]

9. Antonio, M.; David, C.; Alvaro, A.; Javier, A.; Alba, R.; Kewei, Z. Monitoring and wildland early fire detection by a hierarchical wireless sensor network. J. Sens. 2016, 40, 1687-7268.

10. Hu, X.; Ban, Y.; Andrea, N. Sentinel-2 MSI data for active fire detection in major fire-prone biomes: A multi-criteria approach. International. J. Appl. Earth Obs. Geoinf. 2021, 101, 0303-2434. [CrossRef]

11. Alan, A.A.; Michelle, A.D.; Fermin, J.A.; Evers, C.R.; Short, K.C.; Grenfell, I. Predicting paradise: Modeling future wildfire disasters in the western US. Sci. Total. Environ. 2021, 147057, 0048-9697.

12. Basili, P.; Bonafoni, S.; Mattioli, V.; Ciotti, P.; Pierdicca, N. Mapping the atmospheric water vapor by integrating microwave radiometer and GPS measurements. IEEE Trans. Geosci. Remote Sens. 2004, 42, 1657-1665. [CrossRef]

13. Manandhar, S.; Lee, Y.H.; Dev, S. GPS derived PWV for rainfall monitoring. In Proceedings of the 2016 IEEE International Geoscience and Remote Sensing Symposium (IGARSS), Beijing, China, 10-15 July 2016; pp. 2170-2173.

14. Zhang, B.; Chen, Y.; Yuan, Y. PPP-RTK based on undifferenced and uncombined observations: Theoretical and practical aspects. J. Geod. 2019, 93, 1011-1024. [CrossRef]

15. Zhang, B.; Hou, P.; Zha, J.; Liu, T. Integer-estimable FDMA model as an enabler of GLONASS PPP-RTK. J. Geod. 2021, 95, 91. [CrossRef]

16. Zhang, K.; Manning, T.; Wu, S.; Rohm, W.; Silcock, D.; Choy, S. Capturing the signature of severe weather events in Australia using GPS measurements. Remote Sens. 2015, 8, 1839-1847. [CrossRef]

17. Colman, R. A comparison of climate feedbacks in general circulation models. Clim. Dyn. 2003, 20, 865-873. [CrossRef]

18. Zhao, Q.Z.; Ma, X.W.; Yao, W.Q.; Liu, Y. Anomaly variation of vegetation and its influencing factors in mainland China during ENSO period. IEEE Access 2020, 8, 721-734. [CrossRef]

19. Holloway, C.E.; Neelin, J.D. Temporal relations of column water vapor and tropical precipitation. J. Atmos. Sci. 2010, 67, 1091-1105. [CrossRef]

20. Wang, Z.; Zhou, X.; Liu, Y.; Zhang, H.; Sun, W. Precipitable water vapor characterization in the coastal regions of China based on ground-based GPS. Adv. Space Res. 2017, 60, 2368-2378. [CrossRef]

21. Zhao, Q.; Yao, Y.; Yao, W.; Zhang, S. GNSS-derived PWV and comparison with radiosonde and ECMWF ERA-Interim data over mainland China. J. Atmos. Sol.-Terr. Phys. 2019, 182, 85-92. [CrossRef]

22. Ohtani, R.; Naito, I. Comparisons of GPS-derived precipitable water vapors with radiosonde observations in Japan. J. Geophys. Res. Atmos. 2000, 105, 26917. [CrossRef]

23. Vázquez, B.G.; Grejner-Brzezinska, D.A. GPS-PWV estimation and validation with radiosonde data and numerical weather prediction model in Antarctica. GPS Solut. 2013, 17, 29-39. [CrossRef]

24. Abbasy, S.; Abbasi, M.; Asgari, J.; Ghods, A. Precipitable water vapour estimation using the permanent single GPS station in Zanjan, Iran. Meteorol. Appl. 2017, 24, 415-422. [CrossRef]

25. Yahaya, A.A.; Joel, O.B. Appraising the effects of atmospheric aerosols and ground particulates concentrations on GPS-derived PWV estimates. Atmos. Environ. 2018, 193, $24-32$.

26. Guo, M.; Zhang, H.; Xia, P. A method for predicting short-time changes in fine particulate matter (PM2.5) mass concentration based on the global navigation satellite system zenith tropospheric delay. Meteorol. Appl. 2020, 27, e1866. [CrossRef]

27. Wen, H.; Dang, Y.; Li, L. Short-Term PM2.5 Concentration Prediction by Combining GNSS and Meteorological Factors. IEEE Access 2020, 8, 115202-115216. [CrossRef]

28. Guo, J.Y.; Hou, R.; Zhou, M.S.; Jin, X.; Li, C.M.; Liu, X.; Gao, H. Monitoring 2019 forest fires in southeastern australia with GNSS technique. Remote Sens. 2021, 13, 386. [CrossRef]

29. Bowman, D.M.; Williamson, G.J.; Abatzoglou, J.T.; Kolden, C.A.; Cochrane, M.A.; Smith, A.M. Human exposure and sensitivity to globally extreme wildfire events. Nat. Ecol. Evol. 2017, 1, 58. [CrossRef]

30. Liang, J.J.; Calkin, D.E.; Gebert, K.M.; Venn, T.J.; Silverstein, R.P. Factors influencing large wildland fire suppression expenditures. Int. J. Wildl. Fire 2008, 17, 650-659. [CrossRef]

31. Peterson, D.L. Fire in Mediterranean ecosystems: Ecology, evolution and management. Cambridge University Press. Fire Ecol. 2014, 10, 86-87. [CrossRef] 
32. Hersbach, H.; Bell, B.; Berrisford, P.; Horányi, A.; Sabater, M.; Nicolas, J.; Radu, R.; Schepers, D.; Simmons, A.; Soci, C. Global reanalysis: Goodbye ERA-Interim, hello ERA5. ECMWF Newsl. 2019, 159, 17-24.

33. Hersbach, H.; Bell, B.; Berrisford, P.; Hirahara, S.; Horányi, A.; Muñoz-Sabater, J.; Nicolas, J.; Peubey, J.; Radu, R.; Dinand, S.; et al. The ERA5 global reanalysis. Q. J. R. Meteorol. Soc. 2020, 146, 1999-2049. [CrossRef]

34. Sun, M.; Guo, J.; Yuan, J.; Liu, X.; Li, C. Detecting lake level change from 1992 to 2019 of Zhari Namco in Tibet using altimetry data of TOPEX/Poseidon and Jason-1/2/3 missions. Front. Earth Sci. 2021, 9, 216. [CrossRef]

35. Larson, K.M.; Levine, J. Carrier-phase time transfer. IEEE Trans. Ultrason. Ferroelectr. Freq. Control. 1999, 46, 1001-1012. [CrossRef]

36. Saastamoinen, J. Atmospheric correction for the troposphere and stratosphere in radio ranging satellites. NRC Publ. Arch. 2013, 15, 247-251.

37. Bevis, M.; Businger, S.; Herring, T.A.; Rocken, C.; Richard, A.A.; Randolph, H.W. GPS meteorology: Remote sensing of atmospheric water vapor using the global positioning system. J. Geophys. Res. 1992, 97, 15787-15801. [CrossRef]

38. Sugawara, J.; Maeda, S.; Otsuki, T.; Tanabe, T.; Ajisaka, R.; Matsuda, M. Effects of nitric oxide synthase inhibitor on decrease in peripheral arterial stiffness with acute low-intensity aerobic exercise. American. J. Physiol.-Heart Circ. Physiol. 2004, 287, 1522-1539. [CrossRef] [PubMed]

39. Wang, Y.Q.; Shi, J.C.; Liu, Z.H.; Peng, Y.J.; Liu, W.J. Precipitable water vapor retrieval and analysis by multiple data sources: Ground-based GNSS, radio occultation, radiosonde, microwave satellite, and NWP reanalysis data. J. Sens. 2018, 2018, 3428303.

40. Qu, W.; Shang, L.; Li, X.; Liu, J. The Quantitative analysis of polycomponent PAHs by netural network based on data synthese and principal. Spectrosc. Spectr. Anal. 2010, 30, 2780-2783.

41. Elsner, J.B. Analysis of time series structure: SSA and related techniques. J. Am. Stat. Assoc. 2002, 97, 1207-1208. [CrossRef]

42. Zhou, M.S.; Liu, X.; Yuan, J.J.; Jin, X.; Niu, Y.P.; Guo, J.Y.; Gao, H. Seasonal variation of GPS-derived the principal ocean tidal constituents' loading displacement parameters based on moving harmonic analysis in Hong Kong. Remote Sens. 2021, 13, 279. [CrossRef]

43. Zhou, M.S.; Guo, J.Y.; Liu, X.; Shen, Y.; Zhao, C.M. Crustal movement derived by GNSS technique considering common mode error with MSSA. Adv. Space Res. 2020, 66, 1819-1828. [CrossRef]

44. Shen, Y.; Guo, J.; Liu, X.; Kong, Q.; Guo, L.; Li, W. Long-term prediction of polar motion using a combined SSA and ARMA model. J. Geod. 2018, 92, 333-343. [CrossRef]

45. Selby, W.A. Rediscovering the Golden State: California Geography, 2nd ed.; John Wiley \& Sons Lnc.: Hoboken, NJ, USA, 2005; ISBN 9780471732488. 